\title{
EDITORIAL
}

\section{MILITARY FAMILIES: THE PROFESSION'S INVISIBLE BACKBONE}

Last year's final issue of Contemporary Military Challenges, which was dedicated to organizational culture, also included two articles publishing the results of a survey on young people's interest in the military profession. This is a very topical issue as, in the last decade, the Slovenian Armed Forces has been facing a decreasing interest in the military. This is reflected in the gradual reduction in the number of personnel, although the interests of the state in terms of military activities are not reducing quite the contrary. Ever since the beginning of the European migrant crisis in 2015, the Slovenian Armed Forces has been combining its regular functions with additional tasks assigned within the protection of the Schengen border, and recently has been actively involved in the activities around the Covid-19 epidemic.

Nataša Troha and Nuša Gorenak from the Slovenian Armed Forces conducted a survey on a sample of 7,418 high school students and described the results in their article entitled Job characteristics through the eyes of the young generation: survey research "Youth and their motives for the military profession".

Nina Rosulnik and Janja Vuga Beršnak also conducted a survey of 221 male and female students, and presented the results in an article entitled What motivates the young people of the 21 st century to join the military?

The results of both surveys are interesting and very useful for all those involved in the Slovenian Armed Forces' manning efforts. Their task is not easy for a number of reasons. One of the main ones is that the manning of the Slovenian Armed Forces is not only a challenge for the military, but also for the Slovenian state, its government and the state administration. It is a systemic challenge and it should be tackled as such. Interestingly enough, the police have managed to retain the number of their employees compared to previous years, while the Slovenian Armed Forces has not. So, what is the difference between the police and the military as professions? At times 
they seem similar, but again, at other times, we find them completely incomparable. Scientifically, this challenge, among others, is examined by military sociology.

Returning to the research of our four authors and their findings we learn that for young people who do not yet have their own families, the notion of family as a value is a very important factor influencing their choice of profession. Troha and Gorenak established that, from a total of 24 statements, the question of whether it would bother them to be away from family and friends for a long period of time due to work ranked second among high-school students' priorities, with an average score of 3.3 out of 5. Rosulnik and Vuga Beršnak, on the other hand, found that family ranks first among the values that are most important to young students. These facts provide yet another reason to devote more attention to issues related to military families.

In the preparation of our thematic issue, we consequently agreed on a collaboration with Janja Vuga Beršnak, a lecturer and researcher at the Faculty of Social Sciences in Ljubljana, who is project manager of a research project entitled Military specific risk and protective factors for military family health outcomes (J5 1786), funded by the Slovenian Research Agency.

It is true that we are focusing on military families for the first time in the history of Contemporary Military Challenges; however, in military sociology, this has been a long-researched topic. Military families are a very important, though often invisible, pillar of the functioning of every armed forces. The approach to military families is decided by each country, army or commander individually, depending on a variety of factors which will be revealed in more detail in the articles.

In the article Families in the maelstrom of late-modern social changes, Alenka Švab informs us about the general social changes that affect the formation of the family, the roles of mother and father, the birth of children in modern society, and the functioning of the family. We also learn about what essentially interests us in the discussion about military families - how does a military family differ from other modern families?

In the article Military-specific risk and protective factors for military family health outcomes: developing the model, Janja Vuga Beršnak states that both the family and the military are greedy institutions which expect a lot of sacrifice and full-time commitment from the individual. In an individual's efforts to meet the expectations of both, they often find themselves in distress that can jeopardize the health of the individual and his or her family.

In the article The relevance of military families for military organizations and military sociology, Ljubica Jelušič, Julija Jelušič Južnič and Jelena Juvan explain the development of scientific thought in this field and the circumstances that have led to military families attracting research interest in military sociology. They present a historical overview, the current developments, and the dynamics of the 
development of military sociology. It is surprising how much has already been done in this research area, both in the international environment and in Slovenia.

Kairi Kasearu, Ann-Margreth E. Olsson, Andres Siplane and Janja Vuga Beršnak agree with all of the above; however, they point out that the numerous international research studies include relatively little comparative analysis between countries, as it is a particular challenge to select which countries should be included in a sample. In the article Military families in Estonia, Slovenia and Sweden similarities and differences, we can learn more about possible new solutions in the future, as well as about those that cannot be implemented in some countries.

One of these cases is described by Donabelle C. Hess. In her article, Military family readiness: the importance of building familial resilience and increasing family wellbeing through military community support and services, she presents the supporting role of the military community when the entire family moves with a service member to be stationed overseas. In the Alliance, which brings together many countries, service members and their families, cultures and organizational approaches, this is an important task and a great opportunity.

Matej Jakopič writes about the support for military families in his article Structure of the support system for military families in the United Kingdom, Germany and Slovenia, providing another comparative analysis in this area. In his analysis, he compares Slovenia with two larger countries with a much longer military tradition and history, thus revealing some Slovenian peculiarities. He also presents the role of religious and spiritual care for members of the Slovenian Armed Forces.

Family is an extremely important factor that young people consider seriously when deciding to enter a military profession. For those, however, who are already employed in the military, especially in cases where both parents are members of the defence forces, the notion of a military family is of existential importance. 